REIMPRESIÓN

Rev Chil Salud Pública 2015;

Vol 19 (3): 323-334

\title{
MGZ, HOY EDF
}

Como un homenaje a los 60 años de la creación de los Médicos Generales de Zona (MGZ), en este número de nuestra revista reimprimimos un artículo de Cuadernos Médico Sociales de marzo de 1972 titulado "El Médico General de Zona: imágenes de su trabajo, valores ocupacionales y estudio de satisfacción profesional”. Su autora es Ximena Díaz Berr y se trata de un resumen de lo que fuera su tesis de grado como socióloga. Fue premiado en su momento por el Departamento de Salud Pública del Colegio Médico.

Sirvan estas notas como un bosquejo del contexto que se vivía en aquellos años y de lo que representaban entonces los médicos generales de zona. Hace un mes atrás conversamos con Manuel Ipinza, una de las personas que más ha trabajado en formación de recursos humanos en salud. Culminando su carrera, entre el 2008 y el 2014, el doctor Ipinza se desempeñó como coordinador general del Programa de Formación de Especialistas Básicos para la Atención Primaria del Minsal. A raíz de su gran experiencia en el tema es un profesional autorizado para evaluar lo que ha significado la medicatura general de zona en Chile. La información y discusión siguiente es tributaria en mucho de esa conversación.

Detrás de las siglas MGZ se esconde un programa diseñado por Bogoslav Juricic en 1955. Juricic era en ese entonces subdirector general de un nuevo organismo creado en 1952: el Servicio Nacional de Salud. A su cargo tenía la parte operativa del Servicio, llevada a cabo por el conjunto de hospitales, consultorios, y postas que existían por todo el país y en los cuales se realizaría la atención médica definida por la Subdirección Normativa que encabezara Abraham Horwitz.

Esta red de centros de salud se organizó de la mejor manera que se podía en ese momento, siguiendo el esquema clásico de todo tipo de servicios nacionales que coloca unidades de diferente complejidad según la importancia de los distintos centros poblados: cada una más importante que la que le seguía, y jerárquicamente dependiente del nivel que le antecede. Y el problema evidente en ese momento era como se llevaba a los lugares más apartados, y del modo menos compulsivo, a un profesional como el médico, que se había formado luego de una larga etapa, que aspiraba no solo a un nivel de ingresos sino también a estilos de vida que el medio rural no le podía ofrecer. Y es en relación a estas preocupaciones que se creó el programa del médico general de zona: una de las políticas más exitosas de incorporación de recursos humanos a la atención médica.

Yuricic señalaba en $1975^{(\mathrm{i})}$ las condiciones que habían llevado a su creación: el débil desarrollo de la infraestructura física del país, que condenaba a una población rural bastante amplia $(39,8 \%$ en la época de formación del SNS) a vivir mal dotada de servicios básicos (agua potable, alcantarillado, disposición de residuos, etc.), y la escasa y pésima distribución de recursos profesionales médicos, los que en esa época se concentraban en Santiago (65,2\% de los profesionales) y en las principales ciudades del país.

JorGe Gaete

Editor Asociado Revista Chilena de

Salud Pública jagaetea@gmail.com (i). Juricic B, Cantuarias R.La salud rural en Chile: Programa para atraer médicos a las zonas rurales. Boletín de la Oficina Sanitaria Panamericana.1974; 78(3):203-211. 
Se ofreció así una carrera atractiva a médicos jóvenes que ingresaban a un servicio de salud público vasto, variado y prometedor. Los 'generales de zona' podían así acceder a importantes ventajas económicas así como a mayores posibilidades de perfeccionamiento profesional y a desempeñarse progresivamente en localidades más importantes y con mejores recursos. Al cumplir tres años en su destinación original, el general de zona podía optar a trasladarse a algún lugar que contara con un hospital tipo $\mathrm{C}$ o a solicitar una beca de especialización que ofreciera el mismo SNS. Sin embargo, una evaluación del programa hecha in situ -como el artículo que estamos reimprimiendo, y la tesis original de la cual él es un resumen-(ii) indica que la situación real difería de estos propósitos en varios sentidos: el programa no era del todo no compulsivo (este era el único medio por el cual un médico joven podía incorporarse al SNS); los ingresos, sumadas las asignaciones de zona, tampoco eran tan atractivos y las posibilidades de perfeccionamiento, después de los tres años de destinación, no se veían como inminentes.

MGZ: cuesta entender hoy el significado de esas siglas porque aluden a algo que ya no existe; la idea de zona de salud desapareció con la reorganización de la atención médica durante la dictadura militar. A muchos, sobre todo hoy en día, les parece que ese nombre -General de Zona- es un nombre extraño. Aquí la historia viene en nuestra ayuda: él aludía a la práctica de la 'medicina general' que se hacía en alguna de las trece zonas en que se había dividido el país en 1952 al establecerse un sistema estructurado y jerarquizado de centros de salud.

Si bien en los primeros años eran pocos los egresados que optaban por esta carrera, ya en 1966 el 48,1\% de los médicos titulados se contrataban como MGZ. En 1971188 egresados de un total de 322 se contratan como MGZ (58,4\%) y en 1972 son 203 de
$345(58,8 \%$ ). (Yuricic 1975, p. 206). iii Entre 1956 y 1971 es cierto también que los centros de salud localizados en zonas rurales se han incrementado en más del doble, exactamente en un $122 \%$.

Pero, a pesar de que la zona ya no existe, hoy hay una tendencia a reivindicar el nombre por cuanto implica recuperar un estilo de medicina que llegó a ser muy valorado en épocas pasadas y también en la actualidad por algunos sectores. Esta valoración tiene que ver fundamentalmente con lo marcadora que fue la experiencia de la medicatura de zona para la gran mayoría de los MGZ. A muchos el contacto intenso y extenso con la naturaleza física de las zonas alejadas del país, y sobre todo el contacto intenso y extenso con las personas que vivían en esos medios desmedrados, les dejó una marca imborrable en el tiempo y en las distancias. Esa marca tiene que ver especialmente con una fidelidad y una entrega al sistema público de salud que hoy en verdad escasea.

En conversación con Manuel Ipinza, coordinador del Programa de Formación de Especialistas Básicos para la Atención Primaria del Ministerio hasta el 2014, él destaca que en la actualidad, de 1.500 médicos graduados anualmente no más del $10 \%$ opta por la medicatura general de zona. Experiencia exitosa entonces, que hoy se ve constreñida por el hiperdesarrollo de un sistema privado que es congruente con los sistemas de vida predominantes y que no tiene punto de comparación con el desarrollo que tenía el sector privado a inicios de los setenta. No es exclusivamente el dinero lo que hoy divide las aguas: pesan tal vez más las desmedradas condiciones en que se trabaja actualmente en el sector público (cosa por cierto que no es del todo ajena al dinero). Los médicos hoy rápidamente se encaminan a la especialización pensando en el salto profesional al mundo privado.

Aunque con los vaivenes propios de nuestra historia, desde hace 60 años esta política

(ii). Ximena Díaz B. "El médico general de zona: imágenes de su trabajo, valores ocupacionales y estudio de satisfacción profesional”. Tesis para optar al grado de Licenciado en Sociología. Santiago: Universidad de Chile; 1970.

(iii). Esta información es congruente con la indicada en el Informe Hall: "En 1969 se contrataron 136 profesionales, lo que equivale aproximadamente al 50\% de la promoción de ese año” (Recursos humanos de salud en Chile, Ministerio de Salud Pública, 1970, p. 181). 
de formación ha demostrado ser exitosa tanto como herramienta para entregar salud a la población más vulnerable de Chile, como formativa para quienes viven esta etapa. Mejoró el acceso a la atención médica para amplios sectores de la población que, por su ubicación geográfica, no contaban con recursos humanos en salud; y mantuvo ligado al sistema público a un recurso altamente especializado. En este último aspecto incide y en mucho el contacto con la gente sana. Es obvio que el contacto con el paciente hospitalizado solo refuerza la biomedicina clásica; el contacto con la comunidad es lo que hace la diferencia. El doctor Ipinza sostiene, y ha sido su experiencia básica con el Programa de Formación de Especialistas para la Atención Primaria, que es la experiencia de atención en la primera línea la que beneficia al sistema público. "Los becados son estudiantes de excelencia académica, pero además tienen vocación de servicio público y les interesa el trabajo comunitario, les interesa el trabajo en la primera línea. Todos ellos se han quedado en el sistema público. Siguen considerando que tienen una responsabilidad como médicos en la atención en primera línea y con el trabajo comunitario".

¿Cuál es actualmente el destino del médico general de zona? Hoy la población rural en Chile es algo más del 10\%. Pero más allá de la estadística, se trata de una ruralidad conceptualmente distinta: hay otro desarrollo de infraestructura física (nuevas escuelas, nuevos centros de salud, etc.), la interconectividad es otra por los nuevos caminos, por internet de banda ancha. Por este motivo, en la actualidad se está proponiendo generar un médico general de zona urbano para trabajar en la Atención Primaria en Salud. El general de zona empieza a aparecer hoy -en congruencia con los cambios conceptuales de estos tiempos-como una herramienta en la lucha por la equidad en salud. 